\title{
Transformerless Cascaded AC-DC-AC Converter for Multiphase Propulsion Drive Application
}

\author{
Xing-Hua Tao *, Lie Xu **, Yi-Chao Song*** and Min Sun**
}

\begin{abstract}
A transformerless converter suitable for multiphase drive application is presented in this paper. The topology employs a cascaded H-bridge rectifier as the interface between the grid and multi inverters which drive the multiphase motor. Compared with the conventional structure, the new topology eliminates the input transformer and also has the advantages such as four quadrant operation, simple configuration, low cost, high efficiency, and so on. The control strategies for the grid-side cascade $\mathbf{H}$-bridge rectifier and the motorside inverter are studied accordingly. Based on the multi-rotational reference frame, modular control scheme is developed to regulate the multiphase drive system. Simulation results show the proper operation of the proposed topology and the corresponding control strategy.
\end{abstract}

Keywords: Transformerless topology, multiphase motor, cascaded H-bridge converter

\section{Introduction}

In electric ship propulsion application, mega watts motors are needed to provide enough power to drive the ship. For the insulation safety, rated voltages of the motors are restrained. Thus, multiphase motors and drive system are commonly used to realize high power under the limited grid voltage. Compared to three phase motors, multiphase motors have more advantages in reliability and high power density [1]. With the "redundant" stator windings, they can keep the basic function of the motors when stator windings errors are happen, either starting up or working on the degraded rate condition. The more the number of phases, the little the influence of the fault phases made to the whole system. Furthermore, with the configuration of multiphase, the propulsion motor can be more easily designed to realize high power density. It can save more space in the cabin, which is special important in warship propulsion application.

The basic topology of the multiphase motor drive system consists of a diode rectifier and a multiphase inverter. Thus the study on such system is focused on the controlling method of the multiphase motor and inverter. The published literature of multiphase machine and inverter include the

\footnotetext{
* Dept. of Electrical Engineering, Naval Engineering University, China. (taoxh06@mails.thu.edu.cn)

** Dept. of Electrical Engineering, Tsinghua University, China

.(xiliexulie@yahoo.com; mitsun@mit.edu)

*** The 712 Research Institute of CSIC, China. (songyao@163.com)

Received 28 September 2012; Accepted 03 July 2012
}

characteristic of motor with different stator windings [2], modeling of different kind of machines [2, 3], the control strategy and PWM modulation [4 6], fault tolerance [7] and so on. Most of them are based on a two level multiphase inverter which was fed by the common constant dc-link voltage. As medium voltage power system is emerged recently, three-level multiphase inverter is presented to match the medium voltage and the according control method is discussed [8].

In the traditional configuration above, a phase-shift transformer is usually used as the power interface of the system. The transformer can make electric insulation between the grid and the converter, avoiding to the direct contact from high voltage. With phase-drifted secondary windings, it can also efficiently eliminate the grid current harmonics which rectifier-load often brings. Furthermore, it can provide lower output voltages from secondary windings. Thus, the rated voltage of the power device can be decreased. However, the bulky and heavy transformer in such topology brings some problem at the same time. It enlarges the total volume and weight of the whole system; adds difficulties when it is installed in the narrow cabin. Moreover, it causes some additional maintenance burden.

In this paper, a transformerless multiphase drive system is presented. The new topology which is suitable for the multiphase system application, especially for electric ship propulsion is presented. Compared with the conventional one, the proposed topology does not need the isolation transformer, and it can operate in four-quadrant, so the energy can flow bidirectionally between the grid and the 
motor. The volume, weight as well as cost of such a system will be decreased greatly. In part II, the structure of the proposed topology is introduced. Then in part III and IV, the control scheme of the rectifier and multiphase are discussed respectively. Finally, simulation results are given to testify the feasibility of the proposed drive system.

\section{Topology Descriptions}

The proposed topology is shown in Fig.1. An active rectifier and an inverter form an ac/ac converter, which is well known as 'back to back' structure. Such circuit is named 'basic power unit' (BPU). The grid-sides of BPUs are connected in cascade. Then the connected-BPU is linked to one phase of grid through one ac inductance. At the same time, the motor-side of BPUs is linked with multiphase windings. That is the so-called 'single-phaseinput' topology. Such a structure can be extended to 'threephase-input' converter while the inputs of the 'single-phaseinput' topology are connected to the three phase grid in $\Delta$ or Y form. Obviously, the proposed converter is especially suitable for the multiphase motor drive application which windings have multi isolation neutral point. Supposed that into the winding number of the motor is $n$, the number of isolated neutral point is $\mathrm{k}$ and the number of winds which has the common neutral point is $\mathrm{m}$, the relationship among $\mathrm{n}, \mathrm{m}, \mathrm{k}$ can be described as

$$
n=m \cdot k
$$

Usually, multiphase machine has $5,6,9,12,15$ or more phases. Therefore, the possible value of $\mathrm{m}$ and $\mathrm{k}$ may be $\mathrm{m}=3,4,5 \ldots$ and $\mathrm{k}=1,2,3,4 \ldots$. When the multiphase motor is connected to the proposed converter, $\mathrm{k}$ is also the number of the BPU and $\mathrm{m}$ is the number of each BPU's terminal. Therefore, the relationship of $\mathrm{m}, \mathrm{k}, \mathrm{n}$ and the numbers of grid phase $\mathrm{P}(\mathrm{P}=1$ or 3$)$ is $n=P \cdot k \cdot m$.

Compared to the conventional topologies, the proposed configuration has several advantages as following:

(1) As was explained above, the phase-shift transformer is eliminated in such topology and it results in the reducing space, weight and costing requirement;

(2) The cascaded structure is used in the gird side. So the rated volume of the power electronic device is degraded while the converter is connected to the grid directly. Thus, IGBT, IGCT can be used in $10 \mathrm{KV}$ or even higher voltage level application.

(3) The diode rectifier is replaced by the active front end (AFE). Therefore, the energy can flow bidirectionally between the grid and the motor. It means that when the motor is in the braking operation, the energy of the motor will never is burned in the resistor but is fed back the grid, so the particular brake circuit can be omitted and the efficiency of operation will be increased.

(4) AFE can eliminate the grid current harmonic, regulate power factor, which will enhance the efficiency of the whole drive system with the proper control strategy.

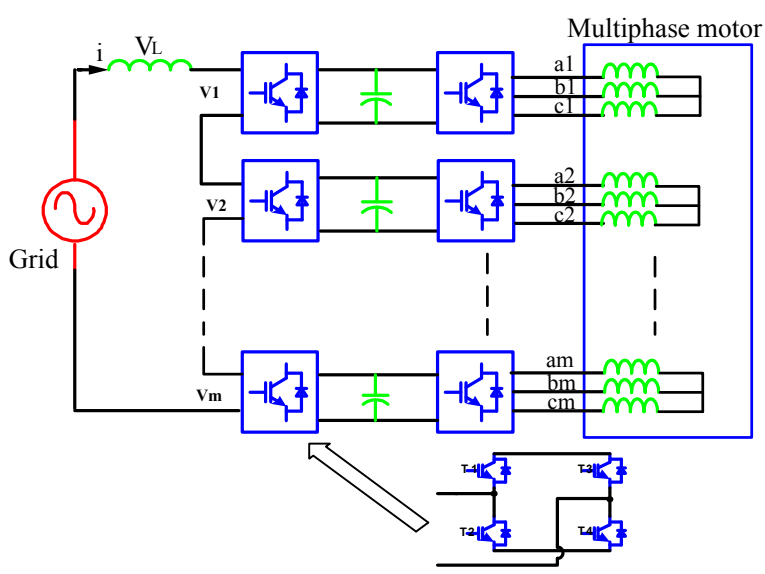

Fig.1. Single-phase-input transformerless multiphase motor drive system

The topology can be divided into two parts: Cascaded Hbridge rectifier (CHBR) and inverter. Both of them have the power device which is trigger by controller. So the control strategy for the converter can also be divided into two accordingly parts, which will be discussed in detail later.

\section{Control Scheme}

For simple, single-phase-input multiphase permanent magnet synchronous motor (PMSM) driver system is studied in this paper, which is shown in Fig.1. Especially, the number of multiphase motor winding is $3 \mathrm{k}$. So, multiphase motor has $\mathrm{k}$ sets three-phase star-connected windings and there are $\mathrm{k}$ BPUs respectively.

When the converter works, two controllers are needed to regulate the rectifier and inverter. The control methods are discussed in the following texts.

\subsection{Cascaded H-Bridge Rectifier}

As seen in fig. 1 , the cascaded $\mathrm{H}$-bridge rectifier (CHBR) is 'one-in-many-out' topology. When CHBR is applied in the multiphase motor drive system, H-bridges have the same parameter and all the output DC voltage should be equal. That is one of the control goals. Another control goal is correcting the input current waveform and regulating its 
phase. In order to achieve unit power factor, the phase of current should be equal to the one of grid voltage.

To simplify the control, the cascaded H-bridges can be equivalent to one H-bridge. Then the traditional PWM rectifier control scheme is introduced to $\mathrm{CHBR}$. The presented control method has two parts: the first one is to shape the input AC current waveform and regulating the total DC voltages of all the cells, the second one is to balance the DC voltage of each cell. The control method is shown as Fig.2.

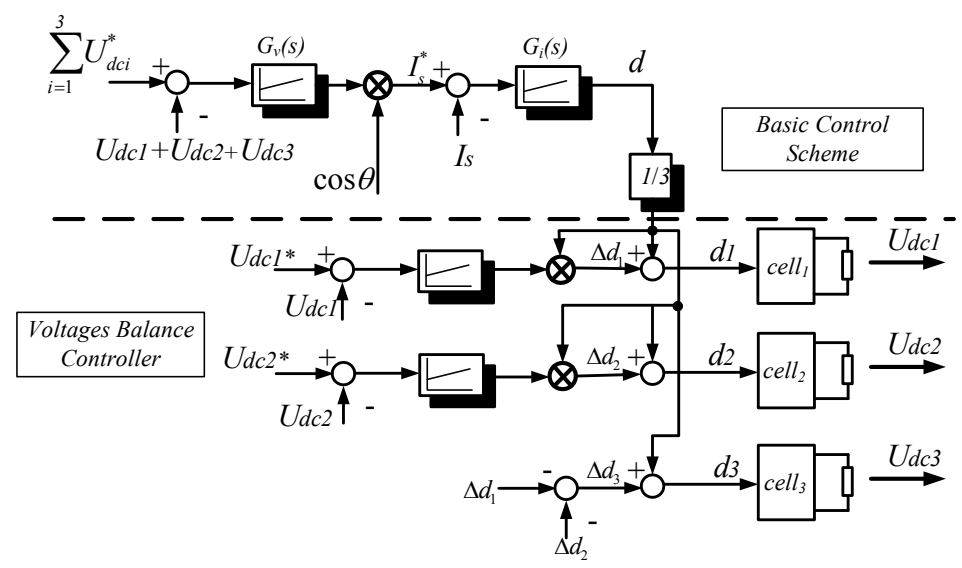

Fig.2. the CHBR control scheme

The current and the total DC link voltage control strategy, which is similar to that of the usual single-phase rectifier, employing double loop control structure shown in Fig.2. The total dc-link voltage is regulated through a PI controller $G_{v}(s)$, the result of which is the magnitude command of the source current. The proportional and resonant $(\mathrm{PR})$ controller $G_{i}(s)$ which is used in the current loop can eliminate the error between the current setting signals and the actual current. The result of the PR controller is the modulation signal $d$. It is obvious that $d$ is the total voltage command signal. In order to regulate the single voltage of each cell, the coming voltage balance algorithm is needed [9].

To balance the DC link voltages means that the power of each unit must match the load power. Therefore, PI-based control scheme is presented and the duty times of each cell are adjusted according to the error of the voltage, which is shown as Fig.2 [10, 11]. According to the proposed method, the voltage error between the demand and feedback value is the input of the PI controller $G_{v i}(s)$. Then the duty bias $\Delta d_{i}$ is got after the output of the controller multiply by the grid voltage. The modulation index of each power unit is the sum of the average modulation index and the bias one.

\subsection{Multiphase motor control}

Since the multiphase motor has $\mathrm{k}$ three-phase windings, it can be seen as $\mathrm{k}$ three-phase motors. Therefore, the proposed topology is equivalent to $\mathrm{k}$ three-phase-motor drive system. Multi synchronous rotating referent frame is introduced in the motor control strategy in this paper. With the strategy, the controllers have the similar structure and they can work independently.

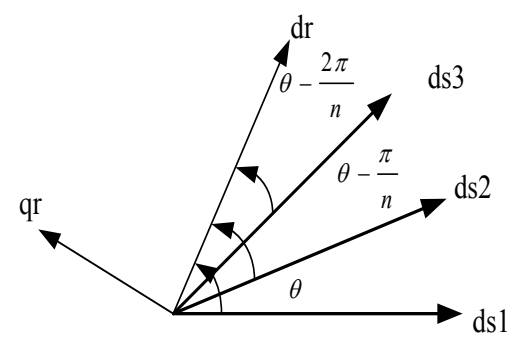

Fig.3. Multi rotate reference frame

The multi rotation reference frame is shown in Fig.3. As $t$ he motor has $n=3 k$ asymmetry stator windings, the shifted $\mathrm{s}$ pace angle between the same winding of the adjacent set is $\pi / n$. Similar to the three phase motor, the modeling of th e multiphase machine can be described as following based on the $\mathrm{m}$ synchronous rotational reference frames:

$$
\begin{aligned}
& u_{s k}=r_{s} i_{s k}+p \psi_{s k}+j \omega_{s} \psi_{s k} \quad k=1,2, . m . \\
& \left\{\begin{array}{cc}
\psi_{k d}=\psi_{r}+L_{k d} i_{k d} & k=1,2, \ldots, m \\
\psi_{k q}=L_{k q} i_{k q} &
\end{array}\right.
\end{aligned}
$$




$$
T_{e}=n_{p} \psi r \sum_{k=1}^{m} i_{k q}
$$

As every set of winding's voltage, current, and the flux c ould map to the same axis through the rotation transformer which the reference frame shifted by $(k-1) \pi / n$ $k=1,2, \ldots m)$, the control scheme was the synthesis of eve ry three winding control block (Fig. 4).
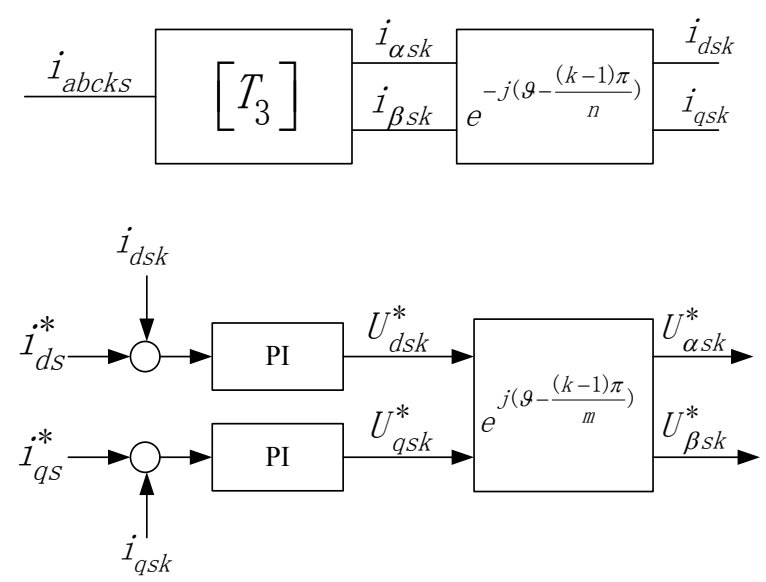

Fig.4. The kth control block $\mathrm{k}=1,2, \ldots, \mathrm{m}$

Such control scheme has the same regulators, and furthermore, they are independent from others. So the proposed control algorithm is special suitable for such system, it can make the whole control body more robust in independence.

\section{Simulation Results}

Simulation is carried out to verify the feasibility of the proposed converter. In simulation, six-phase permanent synchronous motor is driven by a two-BPU converter. The parameters of the $\mathrm{CHB}$ rectifier and the motor are in table1 and table 2 .

Table.1. Parameters of the cascaded H-bridge rectifier

\begin{tabular}{|c|c|}
\hline Switching frequency & $5 \mathrm{kHz}$ \\
\hline Filter inductance (L) & $7.5 \mathrm{mH}$ \\
\hline Filter inductance resistor & $0.2 \Omega$ \\
\hline DC-link capacitor & $2350 \mathrm{uF}$ \\
\hline Voltage source (rms) & $380 \mathrm{~V}$ \\
\hline DC-link voltage references & $540 \mathrm{~V}$ \\
\hline
\end{tabular}

Table.2. Parameters of the six-phase PMSM motor model

\begin{tabular}{|c|c|}
\hline Rotor flux & $1.035 \mathrm{~Wb}$ \\
\hline Stator inductance $(\mathrm{Ld}, \mathrm{Lq})$ & $0.0135 \mathrm{H}$ \\
\hline Leak inductance & $0.005 \mathrm{H}$ \\
\hline Pair poles(np) & 3 \\
\hline Stator resistance & $2.857 \Omega$ \\
\hline Inertia & $0.087 \mathrm{Kgm}^{2}$ \\
\hline
\end{tabular}

The simulation includes three steps. In the first step, the CHB rectifier starts up on no-load condition. Then inverter starts up and the motor run without load at $\mathrm{t}=0.5 \mathrm{~s}$. Finally, load add to the motor at $\mathrm{t}=1 \mathrm{~s}$. Fig.5 Fig. 9 shows the simulation results during the course.

Fig.5 Fig. 7 is about the CHB rectifier. Fig.5 denotes the curves of the control goals (top: DC-link voltages; bottom: grid current) during the three steps. It indicates that DC-link voltages can be well regulated even when the variation of the load happens. Fig. 6 shows the waveforms of the grid voltage and current during the transition when load step up at $\mathrm{t}=1 \mathrm{~s}$. Spectrum analysis is given in Fig.7, grid current's $\mathrm{THD}=1.62 \%$. The simulation results imply that the phase and wave shape of grid current are both well regulated.

Fig.8 10 is about the six-phase PMSM. Fig8 and Fig.9 show the speed and torque curve respectively. At $\mathrm{t}=0.5$, motor is started up and the given speed $(500 \mathrm{rad} / \mathrm{s})$ is active. At $\mathrm{t}=1 \mathrm{~s}$, the given load of the motor steps up from 0 to $40 \mathrm{Nm}$. The speed curve shows that the actual motor speed $\omega_{e}$ tracks the reference speed $\omega_{\text {eref }}$ quickly. The same is to the electric torque. At $\mathrm{t}=1 \mathrm{~s}$ when torque reference steps happen, the electric torque reach the goal value within $0.4 \mathrm{~s}$. Fig.10 shows the stator current of the motor when the load step happen at $\mathrm{t}=1 \mathrm{~s}$.

The simulation results above testify the feasibility of the proposed converter. Moreover, they also validate the proposed control algorithm presented in the final paper.

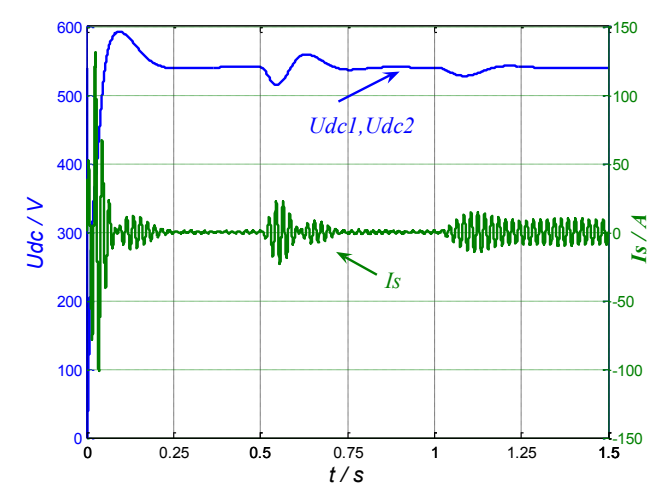

Fig.5. Transient behavior of the CHB rectifier 


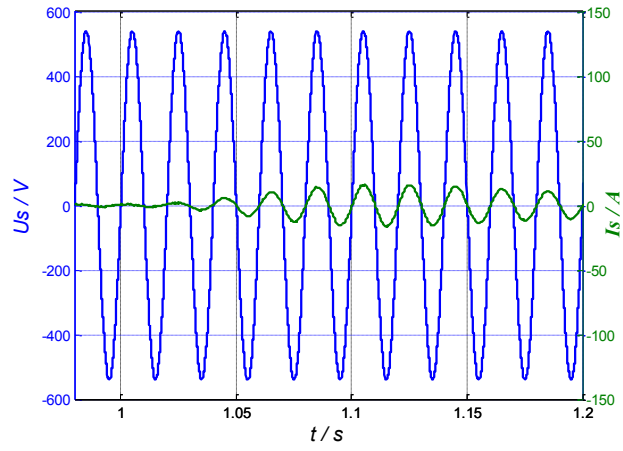

Fig.6. The waveforms of the grid voltage and current

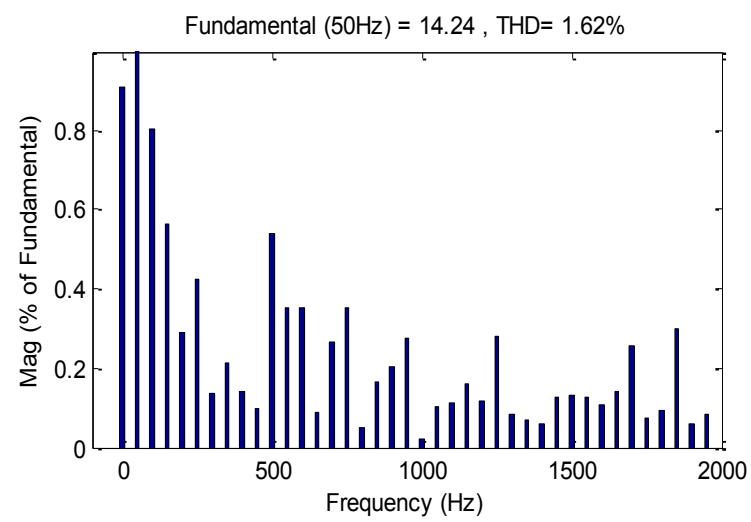

Fig.7. Spectrum analysis for grid current

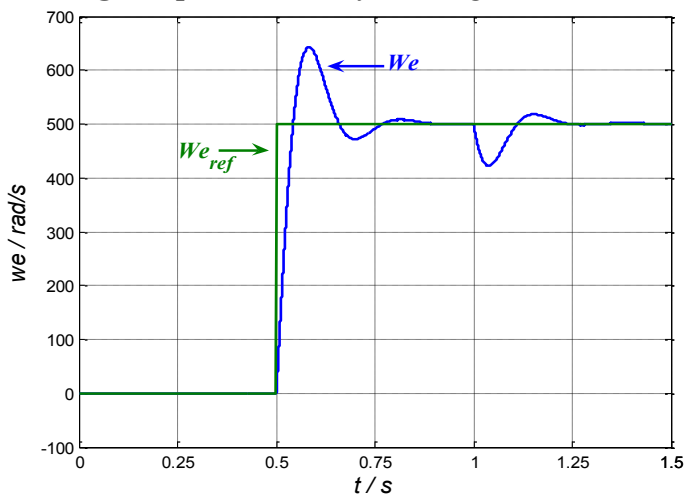

Fig.8. Speed response for startup and step load

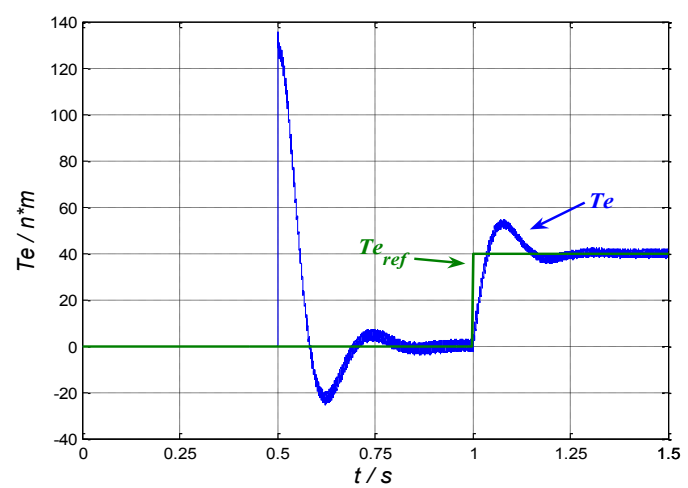

Fig.9. Torque response for startup and step load

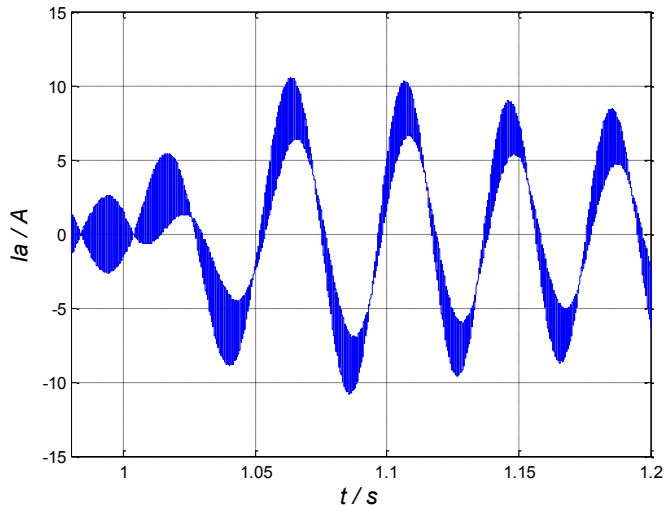

Fig.10. Transient of phase current $i_{a}$ during torque step

\section{Conclusion}

A transformerless multiphase motor drive system used in the electric ship propulsion application is presented. The topology has several identical 'back-to-back' power convert units and it is suitable for the motor which has the same amount independent neural points. Moreover, the control method for the presented system is discussed. In the control solution, two independent controllers are adopted: one for $\mathrm{CHB}$ rectifier and another one for inverter. The control method for CHB rectifier includes total voltage controlling and voltage balance controlling. In inverter control, a multi rotation reference frame is adopted and multiphase motor is seen as multi three-phase motor. Therefore, they can be controlled independently while system is implemented. Simulation model of a single-input six phase PMSM system is built. The simulation results validate feasibility of the proposed topology and the efficiency of the present control algorithm in the paper.

\section{References}

[1] E. Levi, "Multiphase Electric Machines for Variable-Speed Applications", IEEE Trans. Industrial Electronics, 2008, 55(5), pp.1893-1909.

[2] R. H. Nelson and P. C. Krause, "Induction Machine Analysis for Arbitrary Displacement Between Multiple Winding Sets," IEEE Trans. Power Apparatus and Systems, vol. PAS-93, pp. 841-848, 1974.

[3] Z. Yifan and T. A. Lipo, "Space vector PWM control of dual three-phase induction machine using vector space decomposition," IEEE Trans. Industry Applications, vol. 31, pp. 1100-1109, 1995.

[4] X. Huangsheng, H. A. Toliyat and L. J. Petersen, "Five-phase induction motor drive with DSP-based control system," IEEE Trans. Power Electronics, vol. 17, pp. 524-533, 2002.

[5] H. M. Ryu, J. H. Kim and S. K. Sul, "Analysis of multiphase based on multiple d-q spaces concept," IEEE Trans. Power Electronics, 2005, 20(6):1364-1371. 
[6] A. Iqbal and E. Levi, "Space vector modulation schemes for a five-phase voltage source inverter," Power Electronics and Applications, 2005 European Conference on, 2005:12

[7] F. Jen-Ren and T. A. Lipo, "Disturbance-free operation of a multiphase current-regulated motor drive with an opened phase," IEEE Trans. Industry Applications, vol. 30, pp. 12671274, 1994.

[8] L. Shuai, K. Corzine, "Multilevel multi-phase propulsion drive," in Electric Ship Technologies Symposium, 2005 IEEE, pp. 363- 370.

[9] Cecati C, Dell'Aquila A, Liserre M, "Design of H-bridge multilevel active rectifier for traction systems, "IEEE Trans. Industry Applications, 2003, 39(5):1541-1550.

[10] X. H. Tao, Y. D. Li, M. Sun, "A Pi-based control scheme for primary cascaded H-bridge rectifier in transformerless traction converters," in International Conference on Electrical Machines and Systems (ICEMS), 2010 IEEE, pp.824-828.

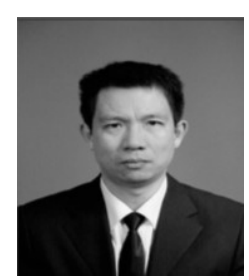

Xing-Hua Tao received Ph.D degree in electrical engineering from Tsinghua university, Beijing, China. His research interests are multilevel converters and electric machines.

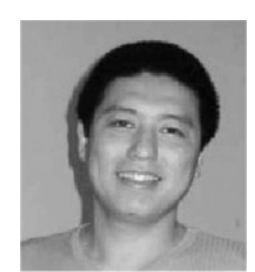

Lie $\mathrm{Xu}$ received $\mathrm{Ph} . \mathrm{D}$ degree in electrical engineering from Nottingham university, Nottingham, UK. His research interests are multilevel converter, matrix converter and electric machines.

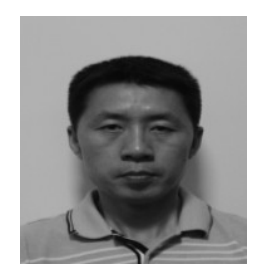

Yi-Chao Song received B.S degree in electrical engineering from Naval Engineering university, Wuhan, China. His research interest is power electronics.

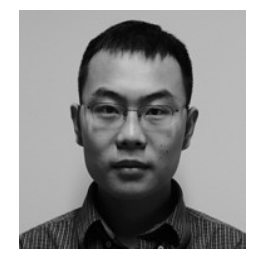

Min Sun received M.S degree in electrical engineering from Tsinghua university, Beijing, China. His research interests are power electronics device and electric machines. 